\title{
Simulation of U-5 Prototype Undulator Effects on the Beam Dynamics
}

\author{
Y. L. Qian and L. R. Turner \\ Argonne National Laboratory \\ Advanced Photon Source \\ 9700 South Cass Avenue \\ Argonne, IL $60439^{1}$
}

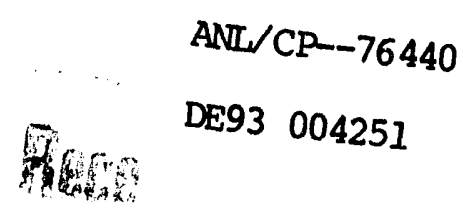

April 6, 1992

\begin{abstract}
The APS prototype undulator U-5 has been installed at NSLS VUV ring. Its effects on the beam behaviour have been simulated with tracking codes TEAPOT and RACETRACK. The tune shift, the distortion of betatron function, the chromaticity, the transverse coupling, and some of the amplitude-dependent effects on the vov ring have been compared and are presented in this paper.
\end{abstract}

\section{INTRODUCTION}

The U-5 undulator is a prototype insertion device for the Advanced Photon Source (APS) storage ring. It is a planar permanent magnet undulator with a period of $\lambda=7.5 \mathrm{~cm}$, maximum field $B_{0}=0.46 \mathrm{~T}$ at a minimum gap of $34 \mathrm{~mm}$; the number of period is 27.5 , so the length of the device is $206 \mathrm{~cm}$. It has been installed in a straight section of the National Synchrotron Light Source's VUV ring. The VUV ring is a fourfold symmetric $750 \mathrm{MeV}$ storage ring. There are four straight sections in the ring. Two straight sections are free for insertion devices. The vertical magnetic field of a insertion device can be approximated ${ }^{[1]}$ :

$$
B_{y}=B_{0} \cosh \left(k_{x} x\right) \cosh \left(k_{y} y\right) \cos (k z)
$$

with

$$
k^{2}=k_{x}^{2}+k_{y}^{2}=\left(\frac{2 \pi}{\lambda}\right)^{2}
$$

where $\lambda$ is the period length of the insertion device and $B_{0}$ is its magnet field. If we assume that the magnet field of the insertion device is uniform in the $\mathrm{x}$-direction, $\mathrm{i}$. e. $k_{x}=0$, then the equation of motion of the electron beam in the vertical plane becomes ${ }^{[2]}$ :

$$
y^{\prime \prime}=-\left(\frac{y}{2 \rho^{2}}+\frac{k^{2} y^{3}}{3 \rho^{2}}\right)
$$

where $\rho$ is the bending radius of the beam with respect to the peak field at the center of the undulator. The first term of equation (3) produces a linear focusing on the beam like

\footnotetext{
${ }^{1}$ Work $u p p o r t e d$ by U.S. Department of Energy, Office of Basic Energy Sciences under Contract No. W-31-109-ENG-38 
a quadrupole. Its strength is proportional to the length of the device and to the square of the field. The second term is an octupole-like component which gives the beam a strong nonlinear effect. In addition to these inherent components, the measured magnet fields of the undulator has about a $100 \mathrm{G} / \mathrm{cm}$ integrated sextupole component and a $10 \mathrm{G}$ skew quadrupole component. All these fields were considered in the simulations. The new RACETRACK (version 4) has included the insertion device function ${ }^{[3]}$ which integrates the equations of motion. In TEAPOT ${ }^{[4]}$ we simulate the full length of the undulator with four quadrupole magnets. The nonlinear part is modeled as a multipole in the middle point along the undulator; the skew quadrupole components are included in the tilt of the undulator quadrupole component.

\section{SIMULATION RESULTS}

\section{1) Tune Shift}

The most sensitive and important effect of the undulator on the beam is the tune shift. The vertical tune shift caused by the undulator is proportional to the undulator field as shown in Fig. 1. The simulation results from both codes are quite close to the measured data as shown in Fig. 1.

\section{2) Betatron Function Distortion}

The distortion of vertical beta function caused by the undulator is shown in Fig. 2. The reiationship of the beta distortion to the undulator field is shown in Fig. 3 . No measured data can be compared to the simulation, but they are both close to the estimated data:

$$
\frac{\Delta \beta_{y}}{\beta_{y}}=\frac{\beta_{y} L_{i d}}{4 \rho^{2} \sin \left(2 \pi \nu_{y}\right)}=9.7 \% \text {. }
$$

The simulation results of the vertical tune shift and betatron function distortion caused by the U-5 undulator are listed below.

Table 1: The tune shift and distortion of $\beta$ function caused by $U-5$ undulator in VUV ring

\begin{tabular}{|l|c|c|c|r|}
\hline$B_{0}(T)$ & \multicolumn{2}{|c|}{$\Delta \nu_{y}$} & \multicolumn{2}{c|}{$\Delta \beta_{y} / \beta_{y}(\%)$} \\
\hline & 1 & 2 & 1 & 2 \\
\hline 0.46 & 0.0144 & 0.0137 & 8.64 & 9.53 \\
\hline 0.345 & 0.0082 & 0.0078 & 4.85 & 5.41 \\
\hline 0.23 & 0.0037 & 0.0034 & 2.15 & 2.46 \\
\hline 0.115 & 0.0009 & 0.0008 & 0.53 & 0.69 \\
\hline
\end{tabular}

1. simulation result from TEAPOT

2. simulation result from RACETRACK 
The beta function in Table 1 is compared at the center of the straight section in TEAPOT and at the maximum beta position in RACETRACK. The tune has been readjusted to the original value in each comparision of betatron function distortion.

\section{3) The Chromaticity}

The measured U-5 undulator field has an integrated sextupole component of about $100 \mathrm{G} / \mathrm{cm}$. The chromaticity change caused by this error component is very small. Figure 4 shows the tune shift versus the momentum change with and without the undulator. Since

$$
\Delta \nu=\xi \frac{\Delta p}{p},
$$

the tune shift caused by chromaticity is propotional to the momentum variation. The simulation results show that the sextupole component of the undulator changes the chromaticity just a little. The chromaticities are $\xi_{y}=-2.7993$ and $\xi_{x}=-3.476$ without the undulator. The vertical chromaticity changes to $\xi_{y}=-2.7647$ with the U-5 device at the peak field. The horizontal chromaticity is actually unchanged at the same time.

\section{4) The Coupling Effect}

The measured undulator magnetic field carries a skew quadrupole component of about $10 \mathrm{G}$. A skew qudrupole will cause coupling between horizontal and vertical betatron motions of the beam. A strong coupling may drive resonances of the type $m \nu_{x}+n \nu_{y}=$ integer. Even far from a resonance a strong coupling will shorten beam lifetime by losing the particles from increased vertical amplitude. A moderate coupling also will lead to increased beam size which degrades the photon beam output. Fortunately, the coupling effects caused by this error component are quite small; however, they can still be seen in the horizontal tune spectrum of Fig. 5 and in the beating of the turn by turn amplitude of the beam (Fig. 6). All these coupling effects are more evident with larger amplitudes of the betatron oscillation.

\section{5) Nonlinear Effects and Dynamic Aperture}

The nonlinear effects of the undulator strongly depend on the betatron amplitude. The vertical phase space in Fig. 7 shows that the chaotic layer will appear in phase space with the larger amplitude. The similar amplitude-dependent effect can also be seen in Fig. 8 for beam smear. Figure 9 shows the tune shift vs the betatron amplitude which is the input value in simulation. The nonlinear effect of the undulator that is of greatest concern is reduction of the dynamic aperture. Figure 10 shows the reduction of dynamic aperture at the peak field of the device. 


\title{
ACKNOWLEDGEMENTS
}

We would like to thank Drs. L. Teng, E. Crosbie, J. Viccaro, and R. Savoy for the support and discussion. Also we wish to thank Dr. S. Kramer for the discussions and for sending us the VUV ring's data, and to Y. Chae for many discussions on the dynamic aperture problems.

\section{References}

[1] K. Halbach, "Physical and Optical Properties of Rare Earth Cobalt Magnets," NIM, 187(1981)109.

[2] P. Kuske and J. Bahrdt, "Influence of the BESSY Undulator on Beam Dynamics," EPAC 90, (1990), pp.1417-1419.

[3] F. Iazzourene et al., "RACETRACK User's Guide, Version 4.00," Sincrotrone Trieste, July, 1991.

[4] L. Schachinger et al., "Manual for the Program TEAPOT," SSC Central Design Group, August, 1991.

\section{DISCLAIMER}

\begin{abstract}
This report was prepared as an account of work sponsored by an agency of the United States Government. Neither the United States Government nor any agency thereof, nor any of their employees, makes any warranty, express or implied, or assumes any legal liability or responsibility for the accuracy, completeness, or usefulness of any information, apparatus, product, or process disclosed, or represents that its use would not infringe privately owned rights. Reference herein to any specific commercial product, process, or service by trade name, trademark, manufacturer, or otherwise does not necessarily constitute or imply its endorsement, recommendation, or favoring by the United States Government or any agency thereof. The views and opinions of authors expressed herein do not necessarily state or reflect those of the United States Government or any agency thereof.
\end{abstract}




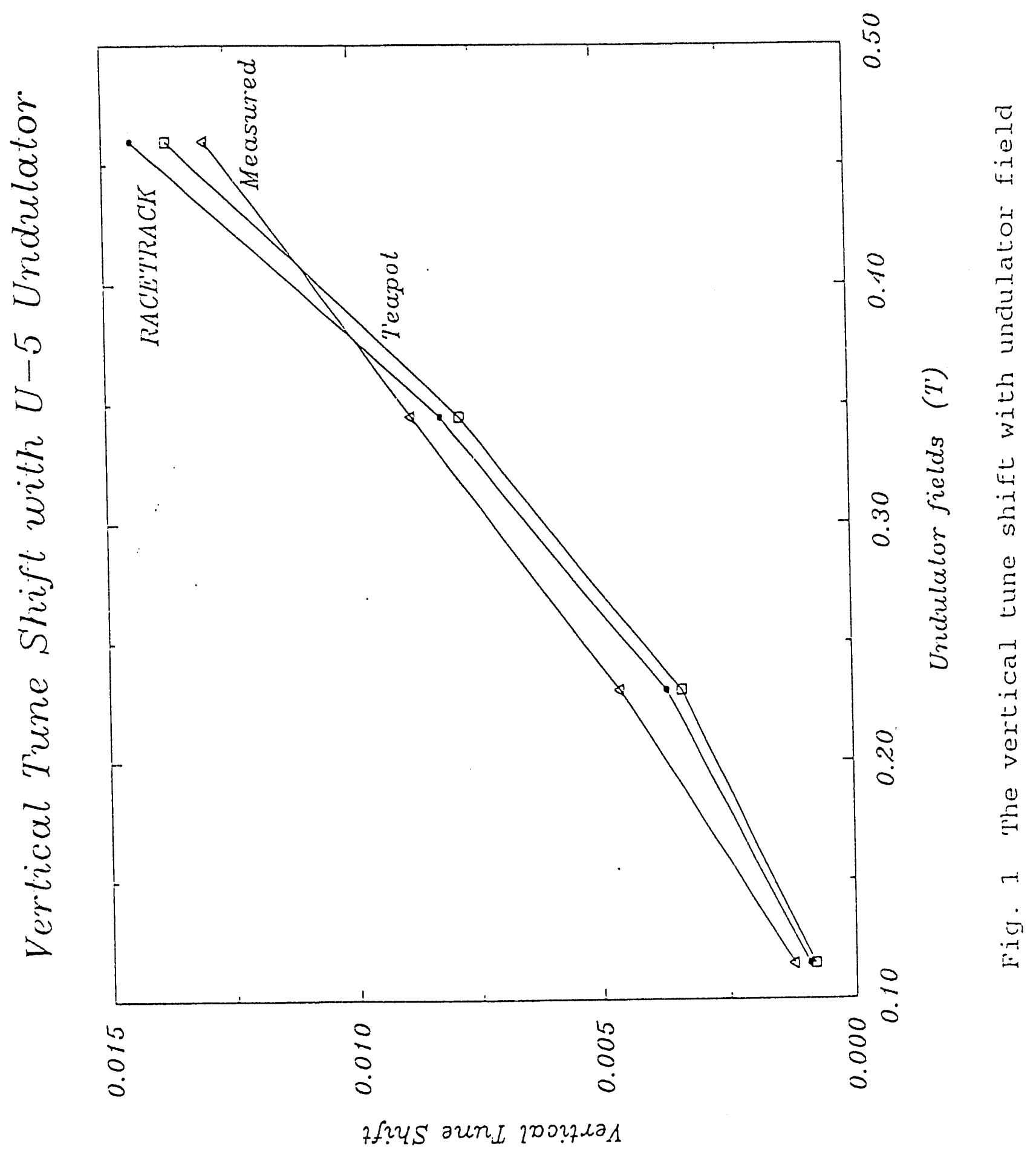




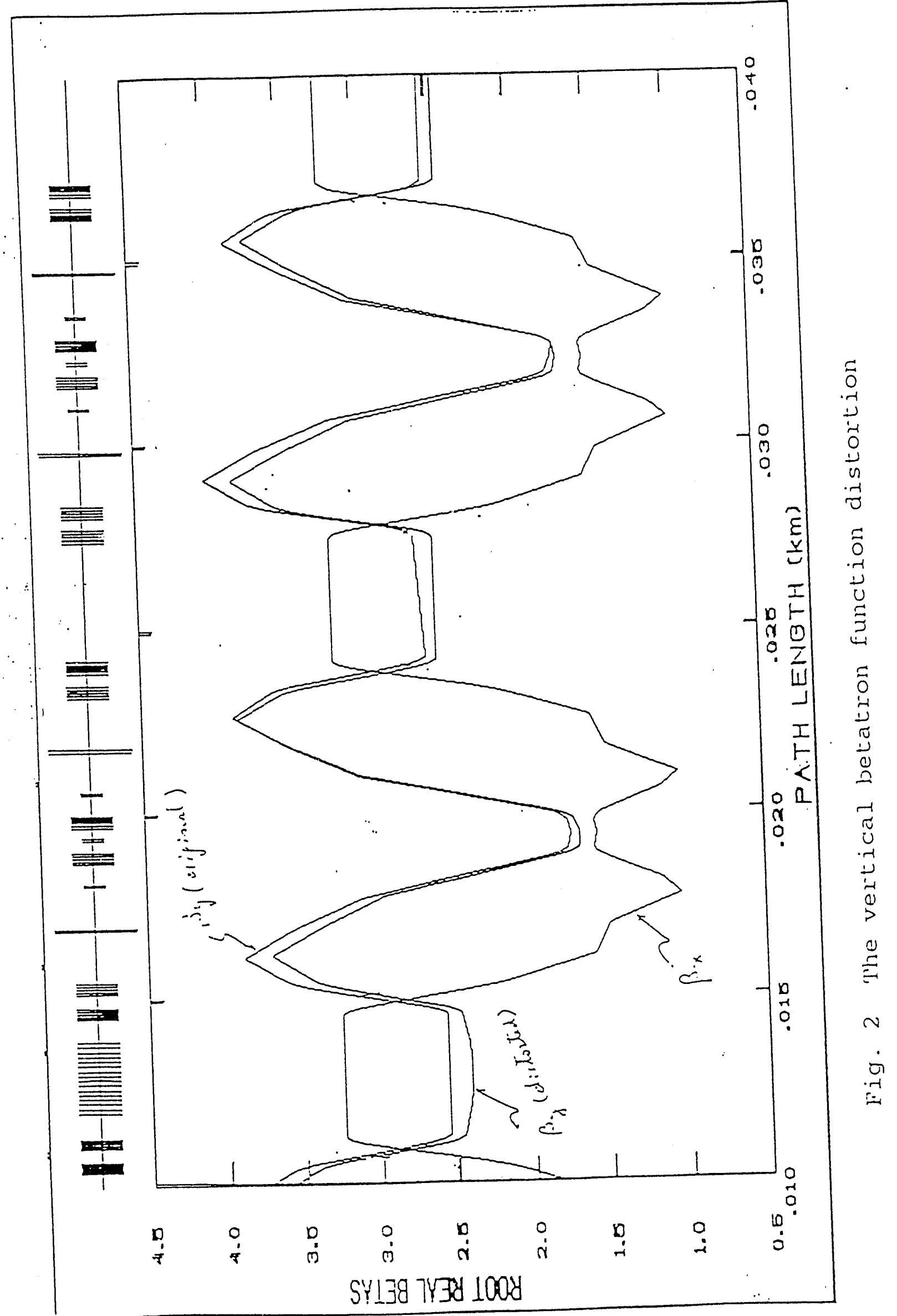




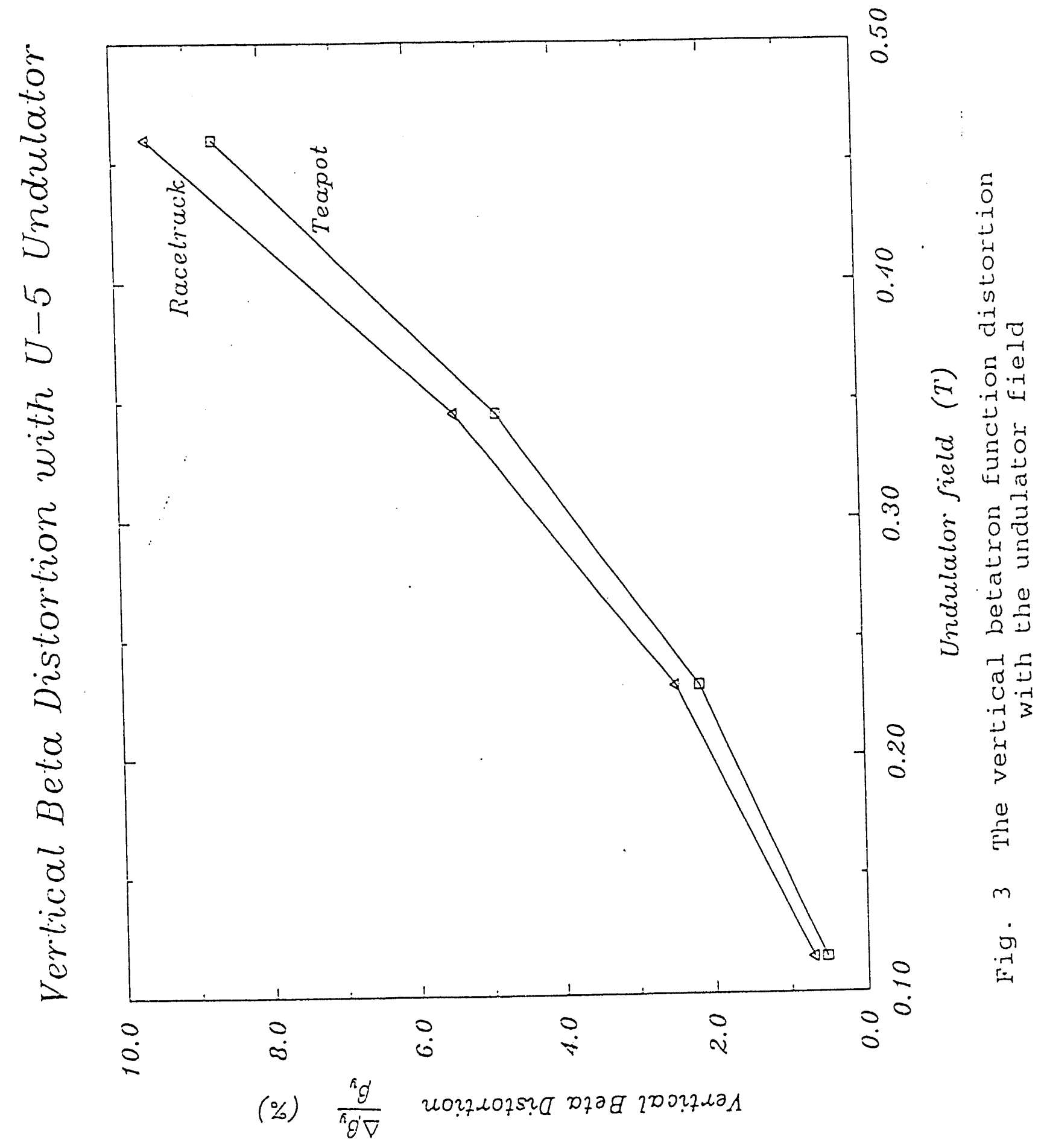




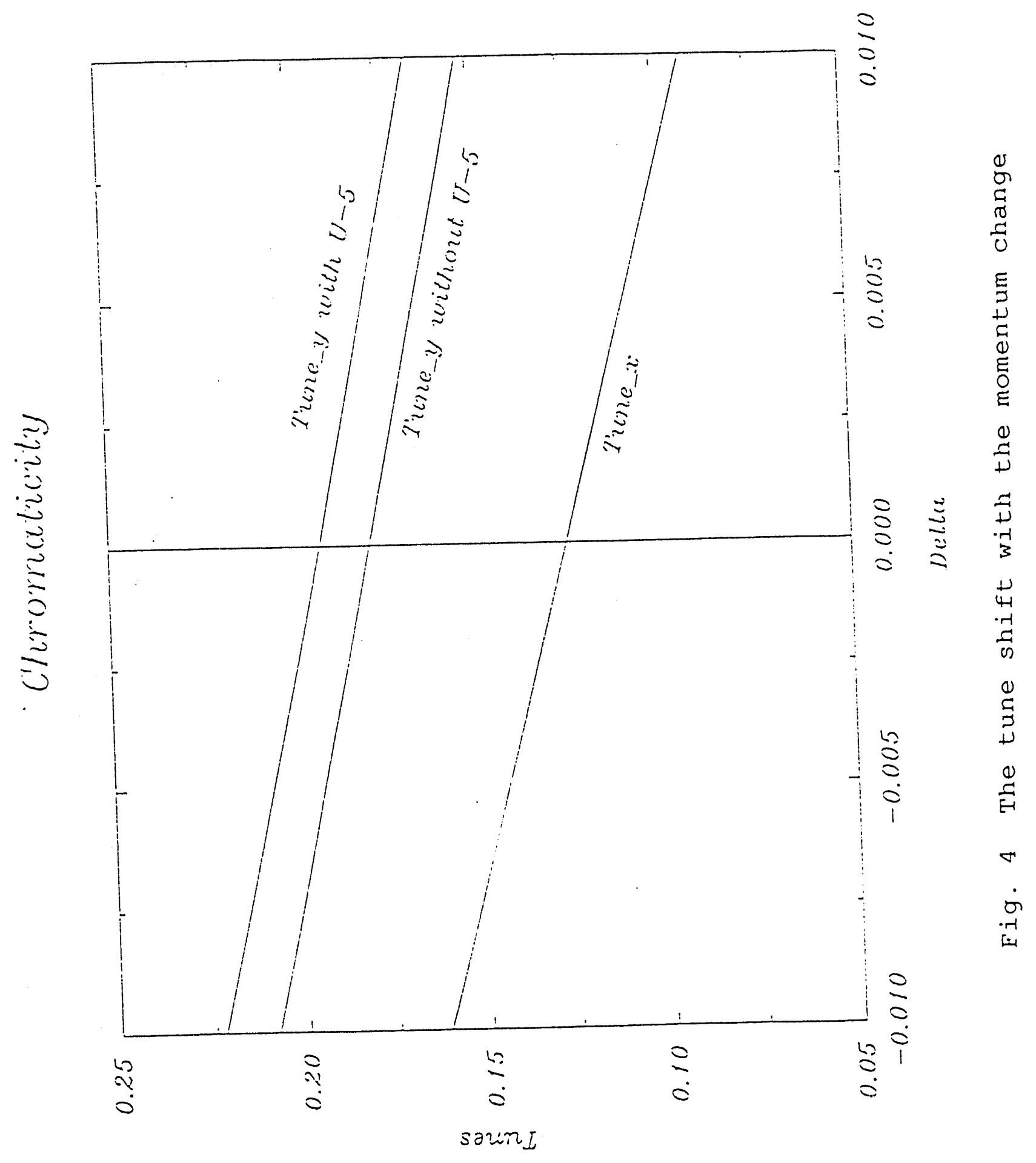




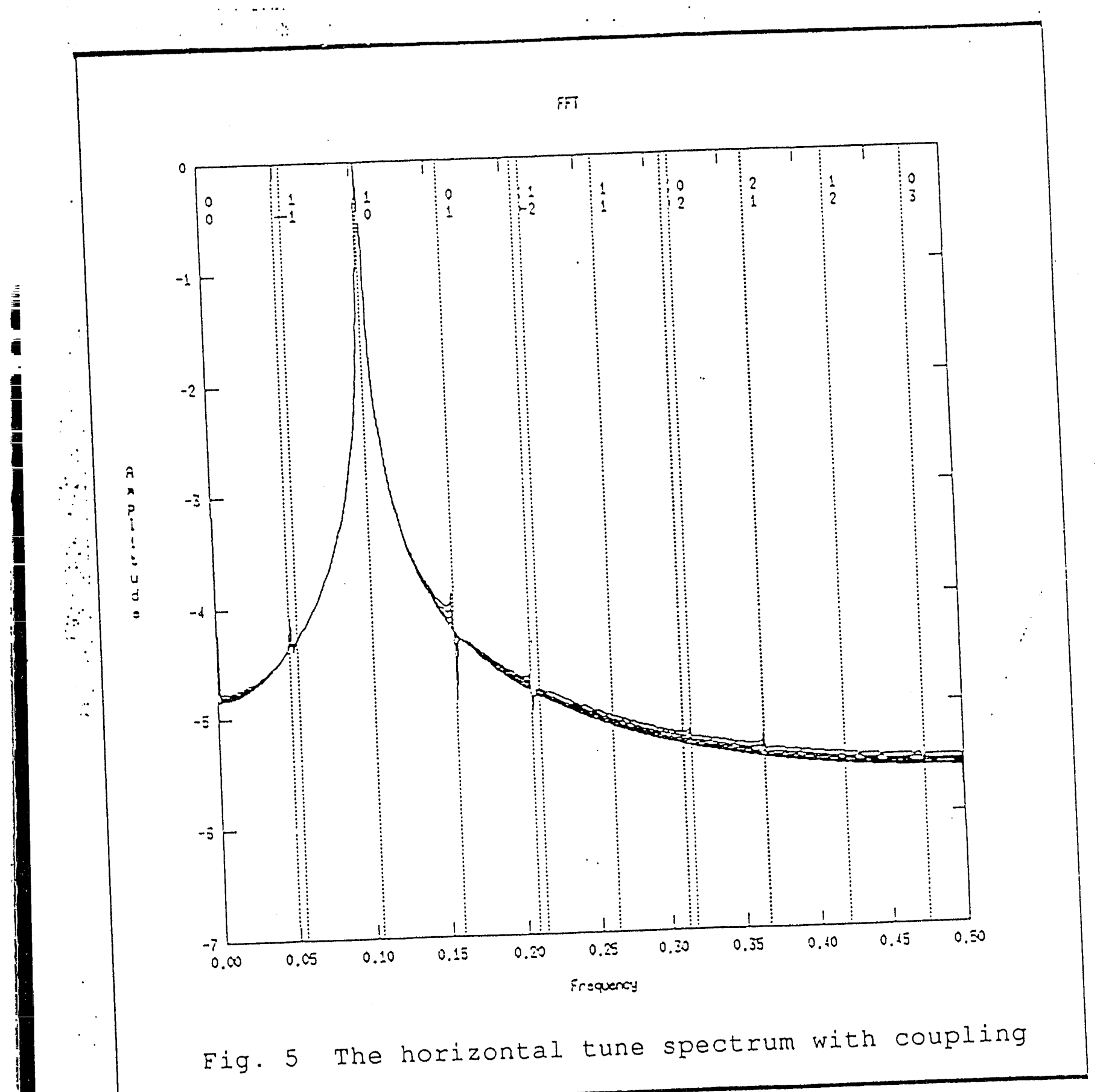




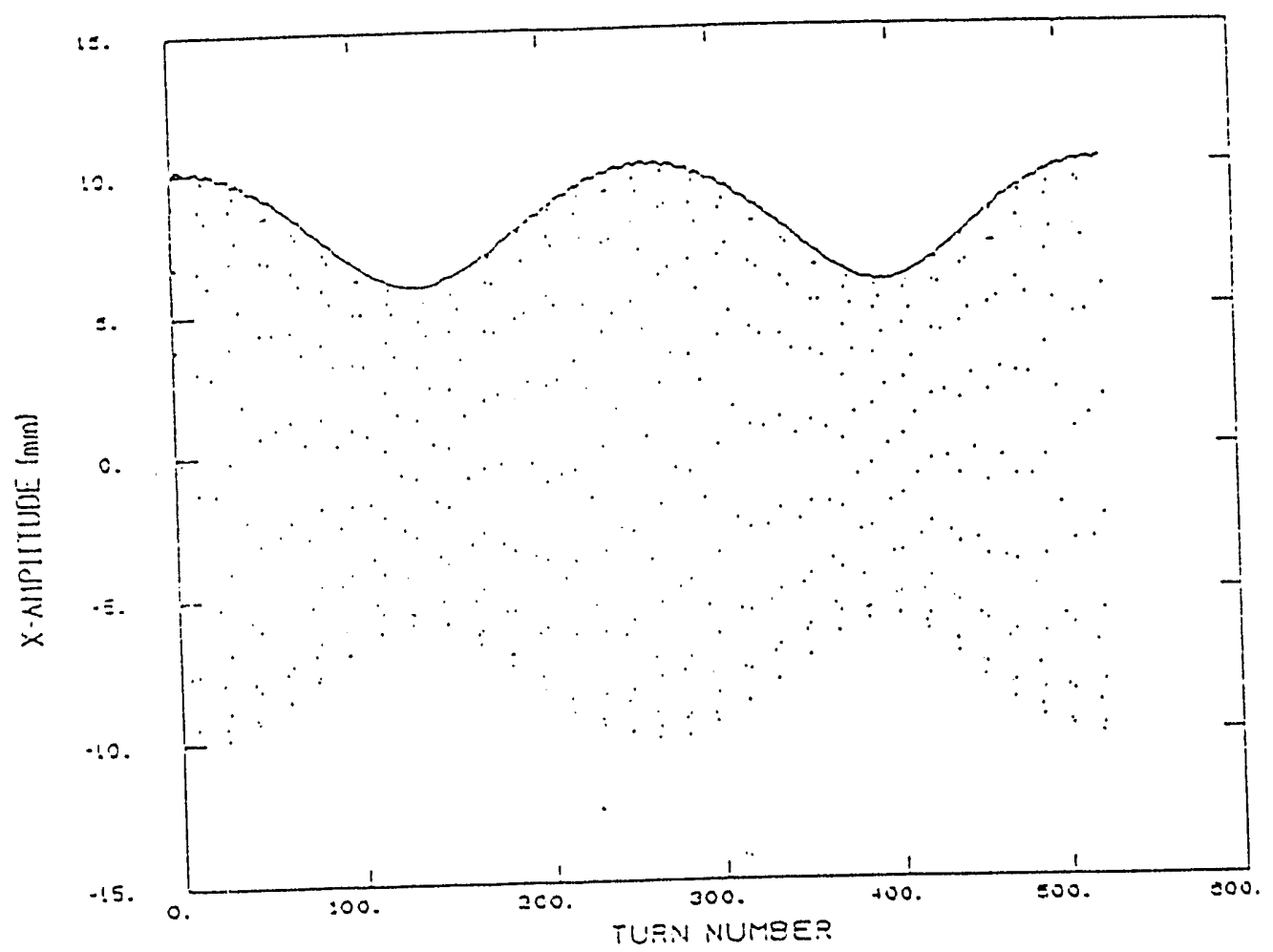

TPANSVEPSE AMPLITUOE

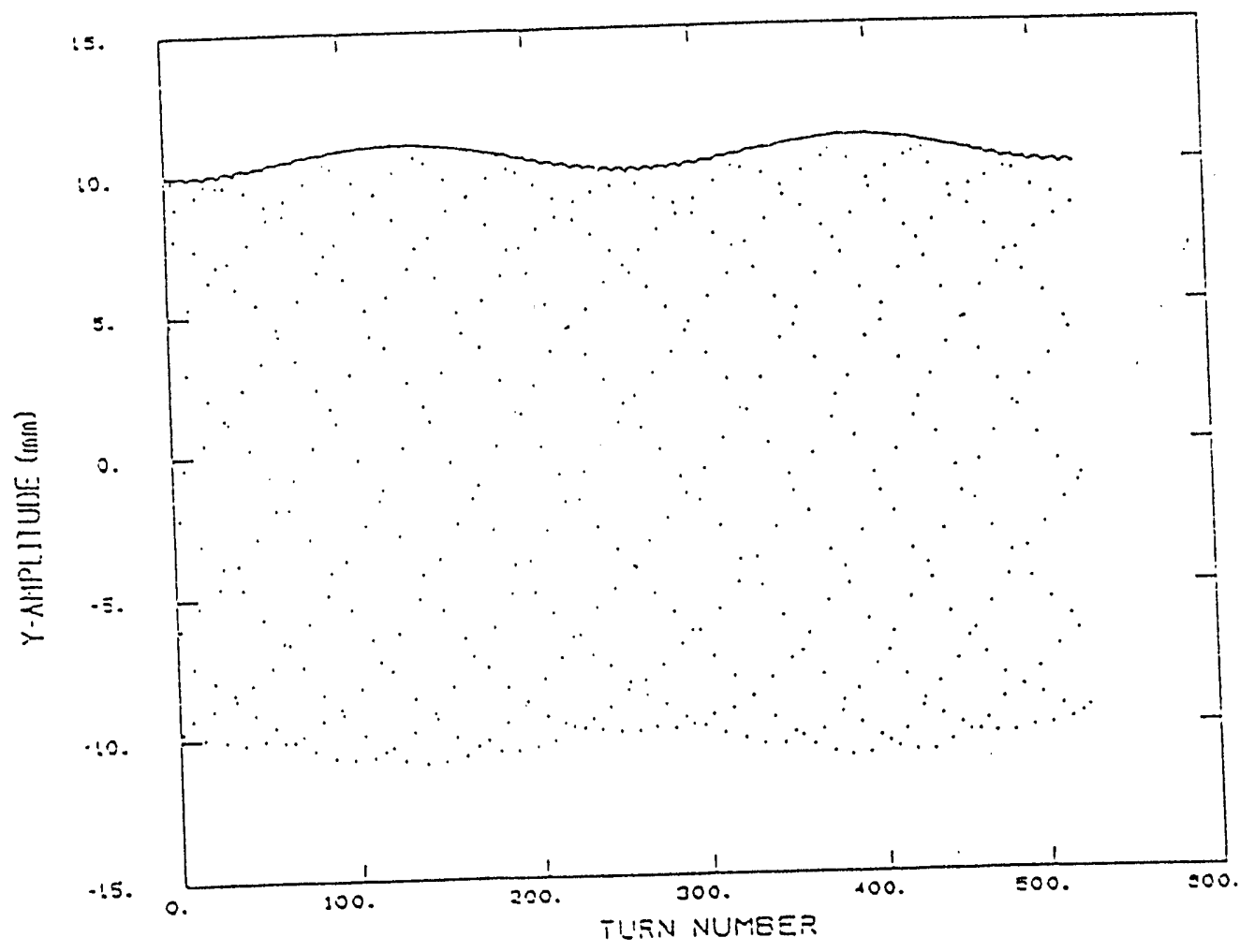

Fig. 6 The coupled betatron oscillation 


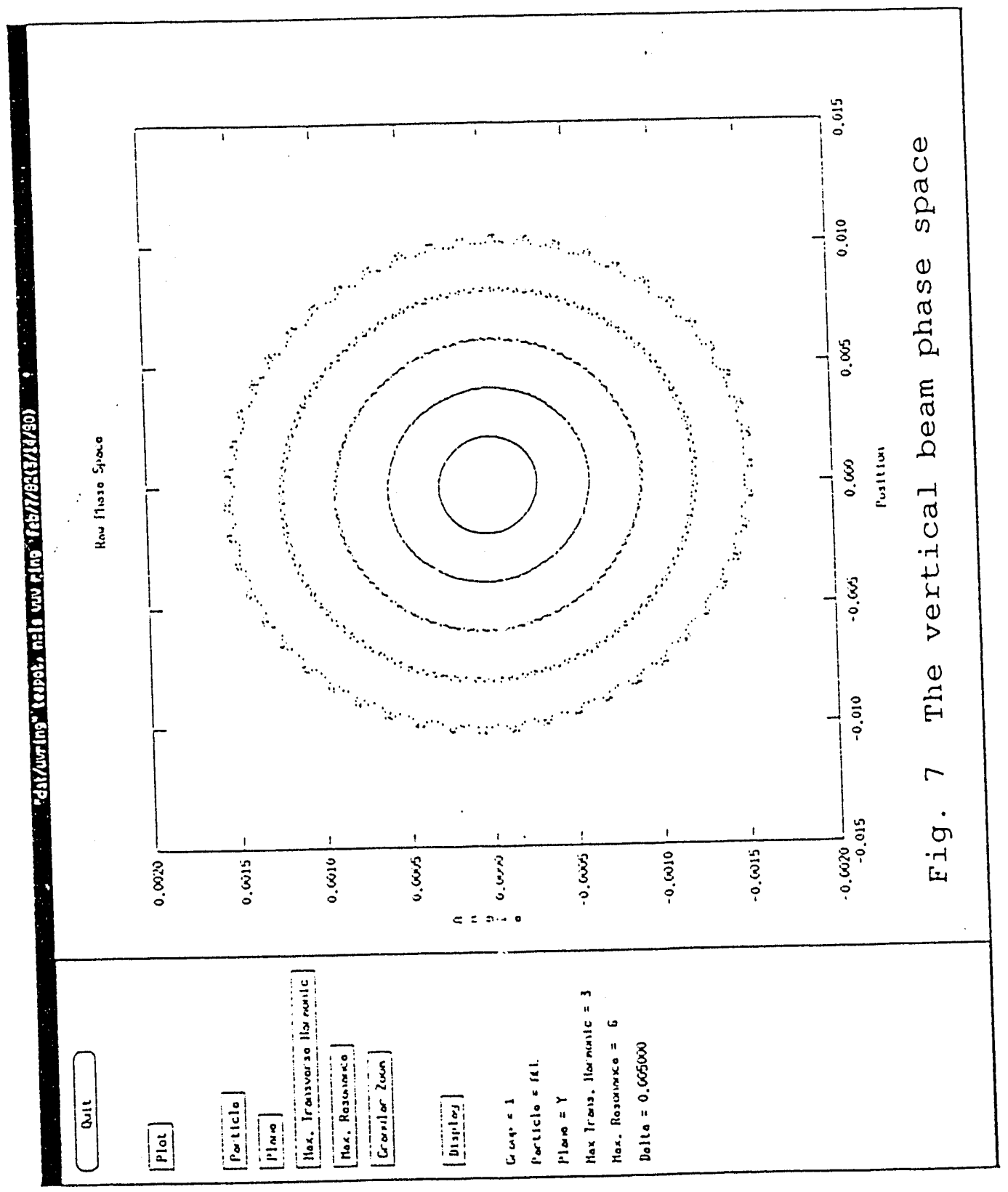




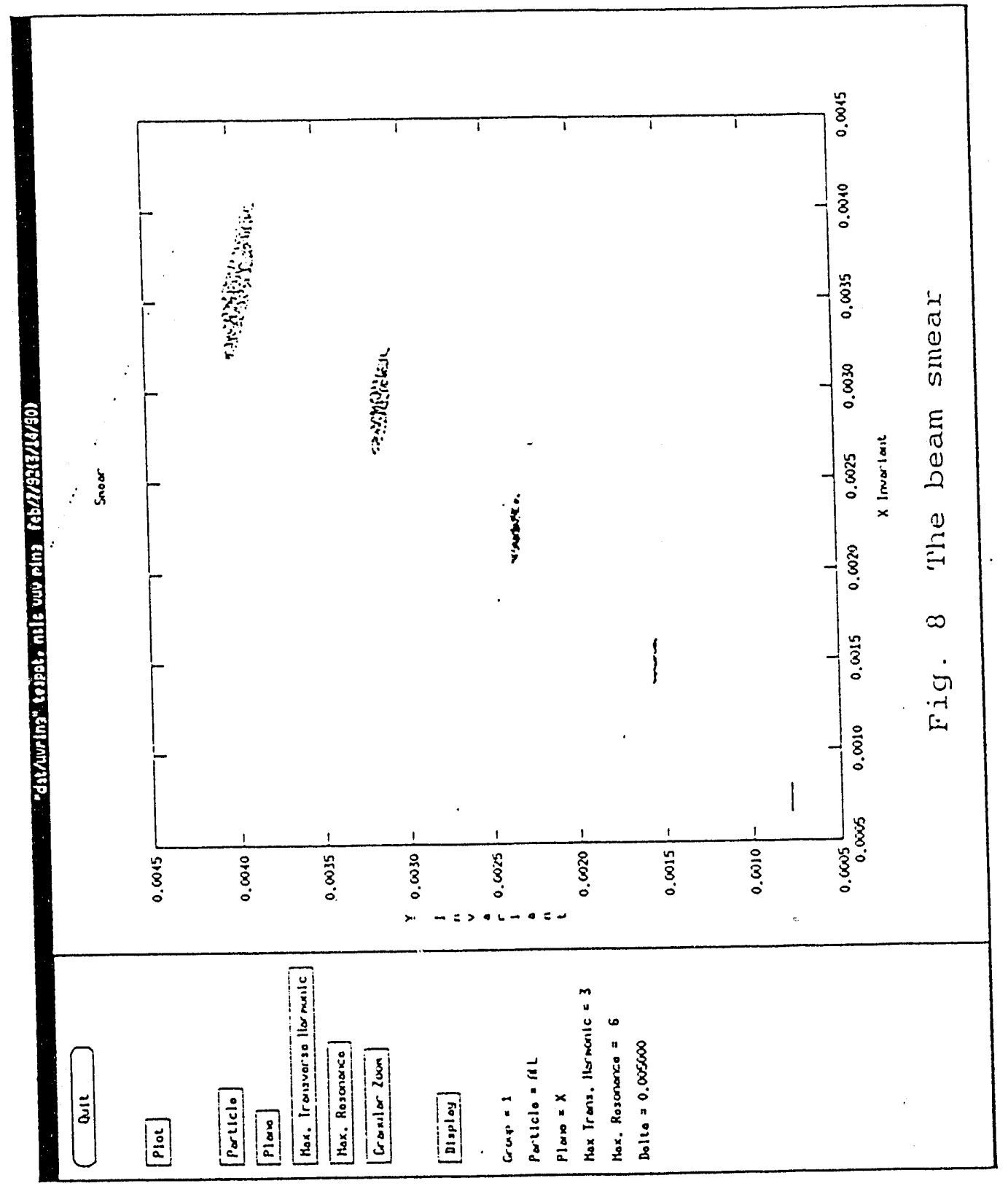




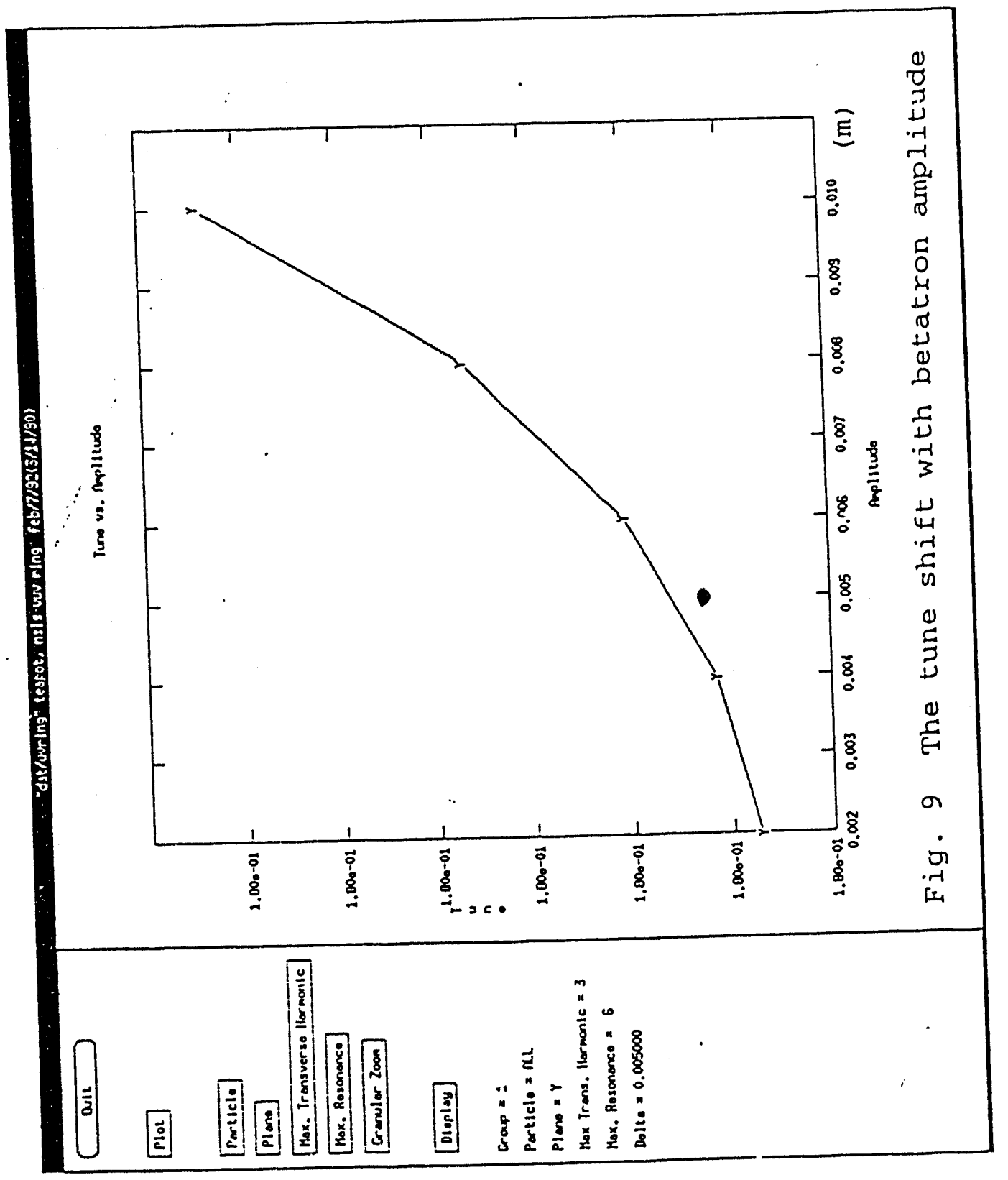




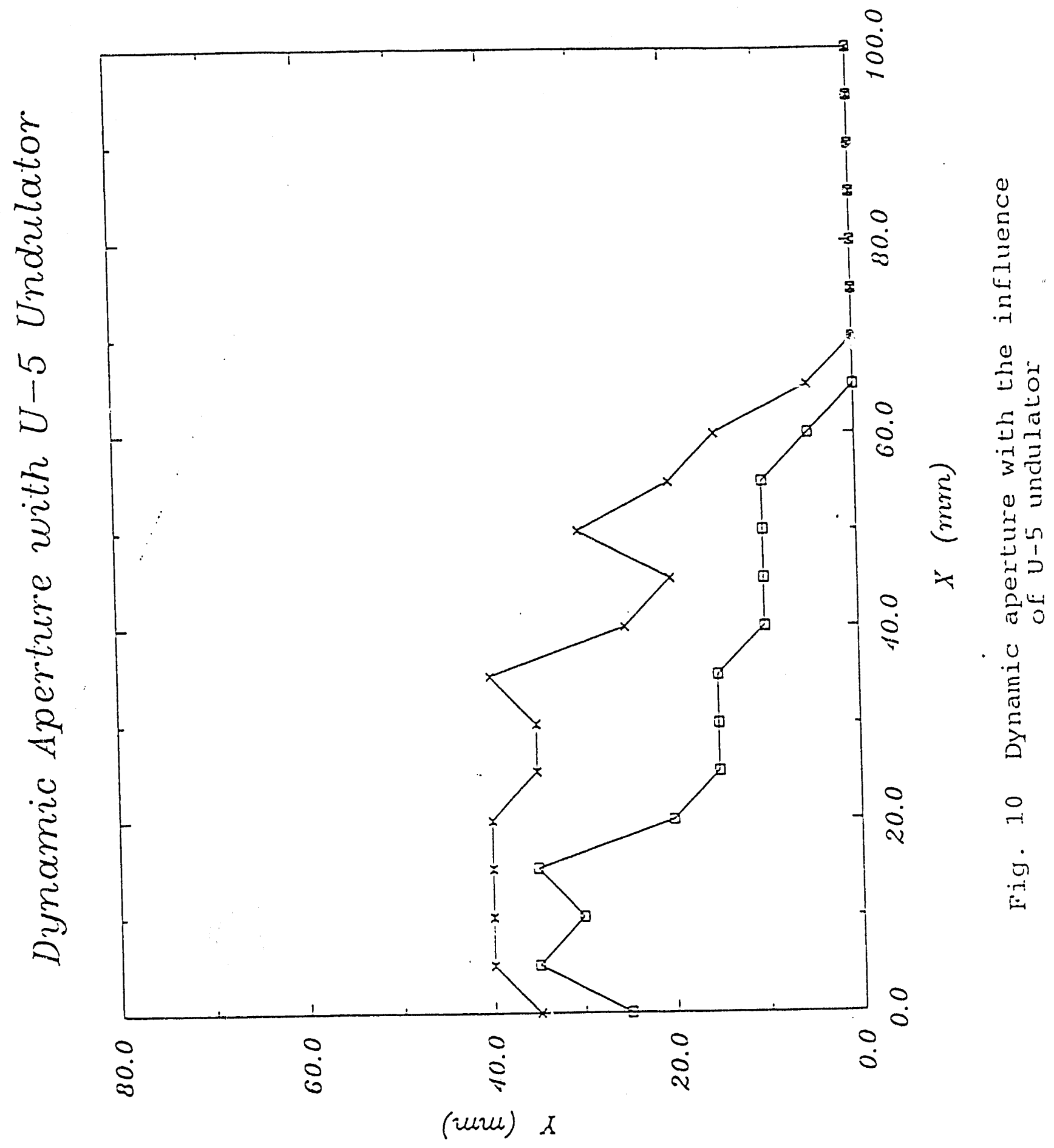



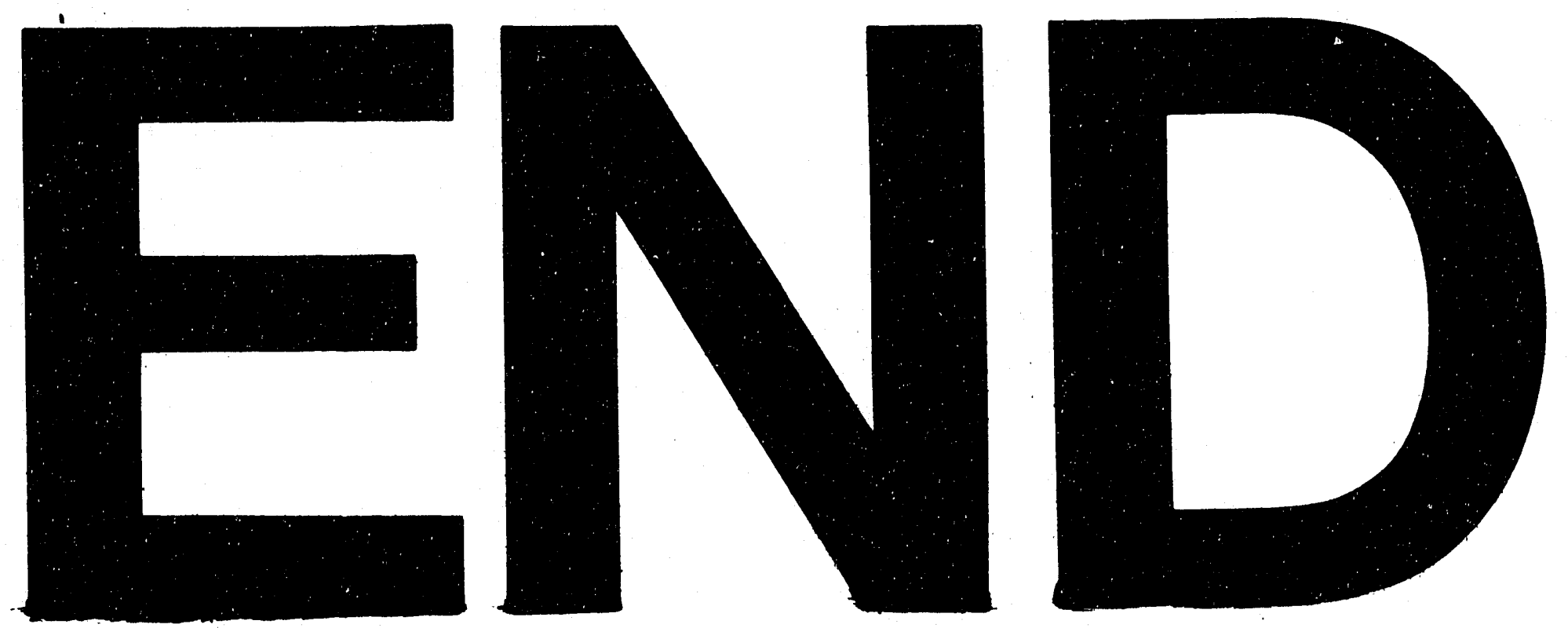

40
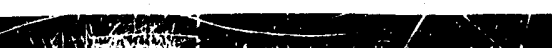
